\title{
Kvanvig on Pointless Truths and the Cognitive Ideal
}

\section{J. Adam Carter}

Received: 15 July 2009 / Accepted: 2 December 2010 / Published online: 13 January 2011

(C) Springer Science+Business Media B.V. 2011

\begin{abstract}
Jonathan Kvanvig has recently attempted to reconcile the problem of (apparently) pointless truths with the claim that the value of truth is unrestrictedthat truth is always and everywhere valuable. In this paper, I critically evaluate Kvanvig's argument and show it to be defective at a crucial juncture. I propose my own alternative strategy for generating Kvanvig's result - an alternative that parts ways with Kvanvig's own conception of the cognitively ideal.
\end{abstract}

Keywords Epistemic value $\cdot$ Truth $\cdot$ Value of truth $\cdot$ Omniscience $\cdot$ Epistemic normativity

\section{Two Kinds of Pointless Truths}

On a wide range of issues, we're after the truth, and when we've got it, it's quite valuable to us; in such cases, there will have been some point to our having found out what we did. But on some issues, we simply don't care on which side the truth falls. Sometimes, our lack of interest in the truth is 'criticisable'. Perhaps not always, though. ${ }^{1}$ Are there any truths such that there would be no point to caring about them, or ever coming to have them? It does seem like there are. Ernest Sosa (2000) offers a description:

At the beach on a lazy summer afternoon, we might scoop up a handful of sand and carefully count the grains. This would give us an otherwise unremarked truth, something that on the view before us is at least a positive good, other things equal. This view is hard to take seriously. The number of grains would not interest most of us in the slightest. Absent any antecedent interest, moreover, it's hard to see any sort of value in one's having that truth. (Sosa 2000, p. 156)

\footnotetext{
${ }^{1}$ These truths which we don't care about, however, wouldn't be thereby pointless truths simply in virtue of our not caring about them. For if they were, then for the student uninterested in history, it would be pointless for him to ever learn about it. And for the man with no interests, it would be pointless to gain any truths at all. This tells us that if some truths really are pointless, this wouldn't be just because we don't care about them.
}

J. A. Carter $(\square)$

Department of Philosophy, University of Geneva, Geneva, Switzerland

e-mail: jadamcarter@gmail.com 
Sosa's grain-of-sand truth really does seem pointless. Plausibly, this pointlessness is not simply a consequence of its being found uninteresting (an attitude which we might have toward truths there would be a point to believe), but instead, a function of a complete absence of any practical (or any other) value that would be generated by believing such a truth.

As Jonathan Kvanvig (2008) has pointed out, pointlessness can be thought of as coming in two varieties: first, there are those he calls basic research truths (e.g. truths about the far reaches of the universe) which have no practical benefit, and in which we inquire just for the sake of expanding our knowledge and understanding. Secondly, there are those truths-such as those about the number of grains of sand on some arbitrary section of a beach-that seem altogether pointless.

Neither basic research truths nor grains-of-sand truths generate any practical benefit. Would there be any value in having such truths? If not, then one consequence is clear: we must reject the thought that truth is always valuable. The view that "truth is valuable," as an unrestricted claim, would be false. A further implication concerns knowledge: it's not clear how one might go about defending the value of knowing some truth that wouldn't itself even be valuable to believe.

The problem raised by pointless truths is one that stands to threaten not only an unqualified endorsement of the value of truth, but also knowledge. Let's consider now the matter of whether pointless truths really do lack value altogether.

\section{Kvanvig on Pointlessness}

\subsection{Crass Pragmatism and Enlightened Pragmatism}

Suppose the answer here is that they do: truths that have no practical value lack value entirely. ${ }^{2}$ Kvanvig calls such a view crass pragmatism and notes a worrying implication: if this line were correct, we'd have no more reason to conduct basic research as we would to count millions of grains of sand on a beach. He points out that:

Noting this implication of the view should give us pause, since, to resort to a bit of hyperbole, nobody in their right mind thinks that only applied research is worth doing. (Kvanvig 2008, p. 11)

This much seems right, and so it must be false that truths that lack practical value thereby lack any value. Perhaps, then, we should be taking a line whereby we could defend basic research truths as more worthwhile than truths about sand on a beach. Kvanvig calls this line enlightened pragmatism. The challenge for the enlightened pragmatist will be to explain why basic research truths are more deserving of our time and attention than paradigmatically pointless truths, even though basic research truths (like grains-of-sand truths) bring about no positive practical value. Here Kvanvig supposes the enlightened pragmatist could point out that basic research is

\footnotetext{
${ }^{2}$ It should be noted that, on this view, there could not be any such thing as purely cognitive value apart from practical value; truths that simply satisfy our curiosity whilst generating no practical value would fail to be valuable truths.
} 
worthwhile because it engenders the possibility or chance of practical benefits, even if not the practical benefits themselves. But that's an untenable claim to defend; a defence would require some argument that distinguishes the grains-of-sand truths from basic research truths by demonstrating the former, but not the latter, to lack the possibility of being worth knowing, and as Kvanvig says:

The appeal to logical or metaphysical necessity lacks the power to sort pointless truths into those that are worth investigating and those that are not.

(Kvanvig 2008, p. 13) ${ }^{3}$

This bring us to an odd predicament: if crass pragmatism and enlightened pragmatism are both untenable, then the only remaining line will be one that offers the following verdict: that even though both kinds of pointless truths lack any practical value, neither lacks value altogether. But if that is right, then we find ourselves wedded to what would seem to be an unwelcome commitment: that counting grains of sand on a beach is not, as Sosa thought, entirely without value.

\subsection{Toward a Strong (Intellectualist) Line}

The intellectualist takes the strong line opposite the crass pragmatist and maintains that no truth lacks value altogether-including basic research truths and truths about the number of blades of grass in your yard. Important to this line is the thought that some truths can have purely cognitive value-value for which the pragmatist positions had no room. The notion of purely cognitive or theoretical value is used by Kvanvig to specify a particular kind of value that is, along with practical value (and other values), part of what determines the value of some truth, all-things-considered. If, as he thinks, the "ubiquitous phenomenon of curiosity" (2008, p. 4) reveals that some of our concerns are purely theoretical, we may think of a truth's cognitive value as value the truth has in virtue of its relationship to these sorts of (theoretical) concerns only, independently of any practical concerns we may have. And so, he maintains, we would go about assessing the purely cognitive value of some truth by controlling for the value it has in virtue of its relationship to non-cognitive, affective states (e.g. desires). The ensuing thought experiment: “...Something has purely cognitive value when it has value to individuals who care about nothing..." (Kvanvig 2008, p. 7).

Pointless truths (of both varieties) lack practical value, but can they have purely cognitive value in the sense just described? If so, then would that be enough to show that pointless truths do not threaten an unrestricted endorsement of the value of truth (and ipso facto knowledge)? This depends. If the claim "all truths are valuable" is supposed to be read as an all-things-considered claim, then even if some positive, purely cognitive value was generated by believing (for example) that there are 34,576 hairs on my head, it's far from clear that this would suffice to ensure that, all things considered, the value generated by my believing this is positive. Quite simply,

\footnotetext{
${ }^{3}$ Kvanvig's point here is that, so long as it's both logically and metaphysically possible that some 'unusual and powerful ruler' (2008, p. 13) made a given truth worthwhile to believe, it's possible that believing such truths would be worthwhile; he claims that the issue is the same when the applied to the notion of 'chance' rather than possibility.
} 
the time and effort it would take me to count all those hairs would prevent me from doing or thinking about a lot of other useful things. It might well be that, all-thingsconsidered, it would have been better for me not to have gained that truth.

This consideration invites the thought that there are, along with pointless truths, bad truths-and further, it might seem that both pointless truths and bad truths stand to undermine the thought that the value of truth (and knowledge) is unrestricted. I contend that Kvanvig makes just the right move here in the way he dismisses the apparent problem of bad truths, and his doing so provides a framework for dealing with pointless truths. Regarding bad truths, Kvanvig admits the obvious point that some truths are, all-things-considered, bad for us to believe; however, he points out that the claim that the value of truth is unrestricted should not be read as an ultima facie claim, but instead, as a prima facie claim. It is, as such, a defeasible claim, and consequently, bad truths are just ones where other negative values serve as overriding defeaters of whatever positive cognitive value was generated. In cases of bad truths, then, negative moral or practical value (for example) could override whatever value was prima facie positive and purely cognitive.

With that said, let us return to the question of whether the two varieties of pointless truths really do have some limited prima facie cognitive value, as our intellectualist line would commit us to. If not, then the problem of pointless truths really does require that we (i) restrict the class of valuable truths to the class of nonpointless truths, and (ii) restrict the class of valuable knowledge so that it includes only knowledge of non-pointless truths.

\subsection{Intellectualism and the Undercutter Model}

On a first pass, the intellectualist programme looks hopeless. The challenge for this programme, recall, was to account for some positive, prima facie cognitive value of not only basic research truths, but pointless truths of the sort that Sosa described. And the latter sort ${ }^{4}$ were ones that seemed to lack not only practical value but any value at all. If that's right, then a dangerous argument lurks: because pointless truths have zero (or an absence of) non-cognitive value (i.e. practical value), the intellectualist can uphold pointless truths as having some positive purely cognitive value only on the pain of maintaining that the all-things-considered value generated by believing such truths is positive. But that would just be to deny flat out that inquiring into some truths really is a waste of time and would leave you no better off.

Kvanvig's move here is to grant the assumption that, in the case of pointless truths, the all-things-considered value is zero; his argument is that the limited, positive prima facie value that is purely cognitive can be undercut-as opposed to overridden-by a complete absence of any other positive values. And so the undercutter model is supposed to explain how pointless truths are compatible with the claim that the value of truth is unrestricted.

A subtle point must be noted here: the undercutter model is not itself sufficient for escaping the problem of pointless truths. All it does is show that prima facie positive cognitive value could be undercut in a way that is consistent with the thought that,

\footnotetext{
${ }^{4}$ From here on, the relevant variety of pointless truths will be the latter, more threatening sort-and I'll be referring to those specifically as pointless truths.
} 
for pointless truths, there is no value generated by believing them whatsoever. The undercutter model will be useful for escaping the problem of pointless truths only if utilized in conjunction with some independent argument that establishes pointless truths as the ones that really would have some prima facie positive cognitive value which is defeated (undercut) by the absence of any other positive values. The burden of the intellectualist is to show that pointless truths actually have some prima facie positive value that gets undercut-as opposed to simply lacking any prima facie positive cognitive value in the first place.

\subsection{The Cognitive Ideal Argument}

At this point in the problem, Kvanvig's move is, I think, especially interesting, and it will be the primary focus of what follows. If it works, then coupled with the undercutter model, he's given us a recipe for explaining away the problem of pointless truths whilst upholding an unrestricted endorsement of the value of truth. But how could anyone manage to argue, without begging the question, that all truths, including pointless truths, have some prima facie, purely cognitive value?

His strategy is not to look at pointless truths and try to find value, but instead to look at one who has cognitively valuable truths and try to find pointless ones:

We should ask ourselves what the cognitive ideal would involve. Here the intellectualists have millennia of theological reflection on their side. Part of the cognitive ideal, whatever else it may involve, is knowledge of all truths; omniscience, for short. But for omniscience to be part of the ideal, no truth can be pointless enough to play no role at all in the story of what it takes to be cognitively ideal. (2008, p. 18)

We can formalize this argument as follows:

\section{Cognitive Ideal Argument}

1. The cognitive ideal consists in knowing all truths.

2. If some truth plays a role in the story of what it takes to be cognitively ideal, that truth has at least some purely cognitive value.

3. All truths (including pointless truths) play a role in the story of what it takes to be cognitively ideal.

4. All truths (including pointless truths) have at least some purely cognitive value.

Because (4) in conjunction with the undercutter model vindicate the intellectualist position, we've arrived at the final piece in the puzzle and should now, by Kvanvig's light, have all we need to explain away pointless truths. While the undercutter model is itself perhaps somewhat contentious, I'll not be taking issue with it but rather I'll be taking issue squarely with the cognitive ideal argument. It is, I think, a very clever and intriguing argument, but some of the most intriguing parts of the argument are also those that will reveal it to be defective.

First, consider premise (2); a generalization of the claim would be something like: "If some $\varphi$ plays a role in the story of what it takes to be $\psi$ ideal, then $\varphi$ has at least some purely $\psi$ value." A problem with this generalization implies that enabling conditions, which can play a role in value explanations, would themselves 
have to be value bearers. But as Jonathan Dancy says, "...even if...enabling conditions contribute to the explanation of the value of the whole, they do not do so by way of contributing to that value in the way that the grounding features do." (Dancy 2004, p. 181). If pointless truths enable rather than contribute cognitive value, then we have a straightforward reason to reject (2): pointless truths, if enablers rather than contributors, could play a role in the story of what it takes to be cognitively ideal without themselves being cognitively valuable.

Even if we were to suppose that pointless truths actually do contribute rather than merely enable cognitive value-a point Kvanvig would need to argue for-there is yet a deeper problem with the cognitive ideal argument, which is premise (1).

Consider an alternative to (1):

\section{(1)* The cognitive ideal consists in being "omni-knowledgeable."}

Let's suppose that one is omni-knowledgeable if one can know whatever one wants to know whenever one wants to know it. This is an impressive property, and on closer inspection, it's not at all clear why omniscience would be more apt to the cognitive ideal. After all:

Divine omnipotence isn't thought to require of God that he do everything that he is capable of doing. Why then suppose God must know everything he is capable of knowing?

If $(1)^{*}$ is a plausible alternative to (1), then it's easy to see how the cognitive ideal argument collapses; pointless truths and the cognitive ideal would come apart. And even if an omni-knowledgeable being knew all truths, it would be the being's cognitive powers, and not what he knew, that played a part in story for what it takes to be cognitively ideal.

There are other lines of objection, though, to premise (1) which don't require that we account for a being's being cognitively ideal in terms of its cognitive powers. It could be argued that the cognitive ideal is not omniscient on the grounds that the cognitive ideal would know all truths that are not pointless, and of pointless issues, just that they are pointless (whilst not actually knowing the pointless truths themselves). Duncan Pritchard ${ }^{5}$ has suggested such a proposal, and Kvanvig anticipates something similar. His response comes by way of a thought experiment which is supposed to place (1) on unshakeable ground.

\subsubsection{Thought Experiment}

Imagine a world with two beings, each claiming to be cognitively ideal. One is omniscient and the other isn't. The less-than-omniscient being claims to be cognitively ideal in virtue of knowing all the important truths, but the omniscient being demurs. For among the important truths are the claims about what the omniscient being knows that the less- than-omniscient being doesn't know. Even if the issue concerning a given proposition is assumed to be pointless and not worthy of being known, the fact that the omniscient being knows the truth value in question and the less-than-omniscient being does not is itself a distinctive difference between the two beings. Moreover, the specific knowledge in question

\footnotetext{
$\overline{5}$ Thanks to Pritchard for bringing this point up in conversation.
} 
is also an important difference: that the omniscient being knows that the claim is true, for example, and the less-than-omniscient being doesn't, establishes a significant difference in terms of their grasp of the precise nature of the world in which they find themselves. Once one appreciates this result of the thought experiment, one can see why lesser accounts of the cognitive ideal collapse into the stronger account. (Kvanvig 2008, p. 19)

This thought experiment boils down to the following argument.

Let O-truths represent whatever truths distinguish the omniscient being from the less-than-omniscient being.

1. O-truths are among the class of important truths.

2. The less-than-omniscient being must know all O-truths.

3. The less-than-omniscient being knows all O-truths only if he knows what specific knowledge the omniscient being has that the less-than-omniscient being lacks.

4. If the less-than-omniscient being knows what specific knowledge the omniscient being has that he (the less-than-omniscient) being lacks, then the less-thanomniscient being is omniscient.

5. The less-than-omniscient being is (actually) omniscient.

There are several strange things going on in this argument. For one thing, (4) is a logical falsehood. The antecedent is true only if the consequent is false. Also, notice that Kvanvig accidentally commits himself to counting all pointless truths as important truths. This was the move in premises (1), (2) and (3). It gets him the result that the important truth knower must know all pointless truths, but at the expense of eliminating any distinction between truths that are important and truths that aren't. If there's really no distinction, then we're saying nothing different in calling a given truth pointless as important. But not all truths are important (or for that matter, pointless), and so this is unacceptable.

\section{Understanding and the Cognitive Ideal}

If pointless truths are to be shown to have some defeasible cognitive value, we'd need a better argument. I think there is one in the neighbourhood. But first, we have to stop thinking of the cognitive ideal within a narrow framework that leaves us debating what it is that the cognitive ideal would have to know. Knowledge is not the only cognitive achievement befitting the cognitive ideal; understanding is at least an equally important achievement, and one that would plausibly play a necessary role in explaining what makes up the cognitive ideal. After all, it would hardly be cognitively ideal to know all but understand little. ${ }^{6}$ And given the factive nature of understanding, it turns out that

\footnotetext{
${ }^{6}$ Such a case is clearly possible. The possibility is entailed by the fact that one can know propositions $\mathrm{P}_{1}$ $\ldots \mathrm{P}_{\mathrm{n}}$ and yet fail to understand subject matter $\alpha$ where $\alpha$ is something understood only by one who knows $\mathrm{P}_{1} \ldots \mathrm{P}_{\mathrm{n}}$ but also further grasps, for instance, the coherence-making relations between various items of knowledge within $\mathrm{P}_{1} \ldots \mathrm{P}_{\mathrm{n}}$. For example, a student might know-say, through memorisation on the basis of expert testimony, that certain axioms of quantificational logic are true. The student might, however, plausibly fail to understand quantificational logic. The student might fail to grasp the relationship between the axioms that would be requisite for applying quantification logic argument evaluation. It would be hard to accept that the student understands quantificational logic, even though the student knows $\mathrm{P}_{1} \ldots \mathrm{P}_{\mathrm{n}}$.
} 
ideal understanding is, not unlike omniscience, something that will require a wide class of truths.

I should distinguish here two varieties of understanding, as only one will be relevant here. The variety that will not be relevant is what has been called propositional understanding, which refers to instances when it is single propositions, as opposed to wider sets of propositions, that stand as the object of understanding. A familiar usage of understanding in this sense might be cases where someone tells you (perhaps smugly) something you already know. You reply: "I understand that the plane has been delayed." As Berit Brogaard (2005) has noted, propositional understanding collapses into propositional knowledge. Objectual understanding, on the other hand, does not. Objectual understanding has as its objects such things as subject matter but also can take on objects much wider. For example, you can understand a specific subject matter like chemistry, or a broader phenomenon, such as why Scandinavian countries are typically more socialist than their European neighbours.

I offer that, for the purposes of considering how we might characterize the cognitive ideal in terms of what she understands (as opposed to knows), we may evaluate (objectual) understanding along two dimensions.

The first is comprehensiveness. Two historians might both be rightly said to understand how the West was won. But the degrees of comprehensiveness might differ-one historian might have a more comprehensive understanding than the other. The more comprehensive an understanding of some matter, the more befitting of the cognitive ideal.

The second dimension is breadth. Returning to our historians, one might understand the major developments in the Western but not Eastern Intellectual tradition, whilst the other historian might understand both traditions, their similarities, and points of disconnect. Clearly, the sort of understanding befitting the cognitive ideal will be of a maximal breadth.

I'm going to offer a simple argument now:

1. The cognitive ideal consists (at least in part) in cognitively ideal understanding.

2. If understanding could possibly be of a greater breadth than it is, it is not cognitively ideal.

3. If understanding could possibly be more comprehensive than it is, then it is not cognitively ideal.

4. Understanding could be of the greatest possible breadth and the greatest possible comprehension only if encompassing all truths.

5. The cognitive ideal consists (at least in part) in understanding that encompasses all truths.

If this argument is correct, then we'll have escaped the problem of pointless truths, and without the intellectualist audacity of supposing that a cognitively ideal agent would believe them for the sake of believing them. Pointless truths are indeed pointless to believe for the sake of believing. While such beliefs are, in themselves, pointless to have, cognitively ideal understanding is not pointless to have. And given that cognitively ideal understanding encompasses all truths, we have a story for why even pointless truths have some defeasible cognitive value-value which can of course be undercut (in the absence of any other positive values). 
I want to mention a final point about the value of pointless truths, which I hope will clarify the remarks just made. I am conceiving of the value of pointless truths as (defeasibly) cognitively valuable in virtue of their contribution to a whole (cognitively ideal understanding). Unlike Kvanvig, then, I think the unrestricted value of truth is something we can defend only if we think of the defeasible value of pointless truths as contributory value-value that, as Ramon Lemos puts it, "anything has...by virtue of its contributing to the value of some whole of which it is a part." (Lemos 1995, p. 41) I suspect, in conclusion, that one reason the problem of pointless truths has seemed so troubling owes to the tendency to reason as follows: pointless truths lack practical value, and so if they're valuable at all, their value must be cognitive value, and if only cognitively valuable, then we must find some argument to explain why it's valuable to believe them for their own sake. Once these concessions are made, the only way out will be to make some move-as Kvanvig did-which could account for why the value of such truths (even if defeasible) is final value-that is, that there is some limited (defeasible) cognitive value that arises from believing them because believing them is cognitively valuable. I've offered that we resist this sort of stubborn intellectualism, which-as it turned out-wasn't needed after all in order to uphold the milder intellectualist tenet that the value of truth is unrestricted.

\section{References}

Brogaard, B. (2005). I know. Therefore I understand. (unpublished).

Dancy, J. (2004). Ethics without principles. Oxford: Oxford University Press.

Kvanvig, J. (2008). Pointless truth. Midwest Studies in Philosophy, XXXII, 199-212.

Lemos, R. (1995). The nature of value: axiological investigations. Gainesville: University of North Florida Press.

Sosa, E. (2000). For the love of truth. In L. Zagzebski \& A. Fairweather (Eds.), Virtue epistemology: Essays on epistemic virtue and responsibility (pp. 49-62). Oxford: Oxford University Press. 